Supporting Information for:

\title{
NO $_{x}$ Adsorption and Optical Detection in Rare Earth Metal-Organic Frameworks
}

Dorina F. Sava Gallis, ${ }^{\dagger}$ Dayton J. Vogel,,${ }^{\dagger}$ Grace A. Vincent, ${ }^{\dagger}$ Jessica M. Rimsza, ${ }^{\ddagger}$ and Tina Nenoff ${ }^{\star *}$

† Nanoscale Sciences Department, Sandia National Laboratories, Albuquerque, NM 87185, USA.

$\S$ Material, Physical, and Chemical Sciences Center, Sandia National Laboratories, Albuquerque, NM 87185, USA.

‡ Geochemistry Department, Sandia National Laboratories, Albuquerque, New Mexico 87185, USA.

Corresponding Author

*tmnenof@sandia.gov 


\section{Section S1: Powder X-ray Diffraction (PXRD) measurements}

Powder X-ray Diffraction (PXRD) measurements were performed on a Siemens

Kristalloflex D500 diffractometer, $\mathrm{CuK} \alpha$ radiation $(\lambda=1.54178 \AA)$.

Figure S1. X-ray diffraction data for pristine and $\mathrm{NO}_{\mathrm{x}}$ exposed compound 2 after $24 \mathrm{hrs}$.

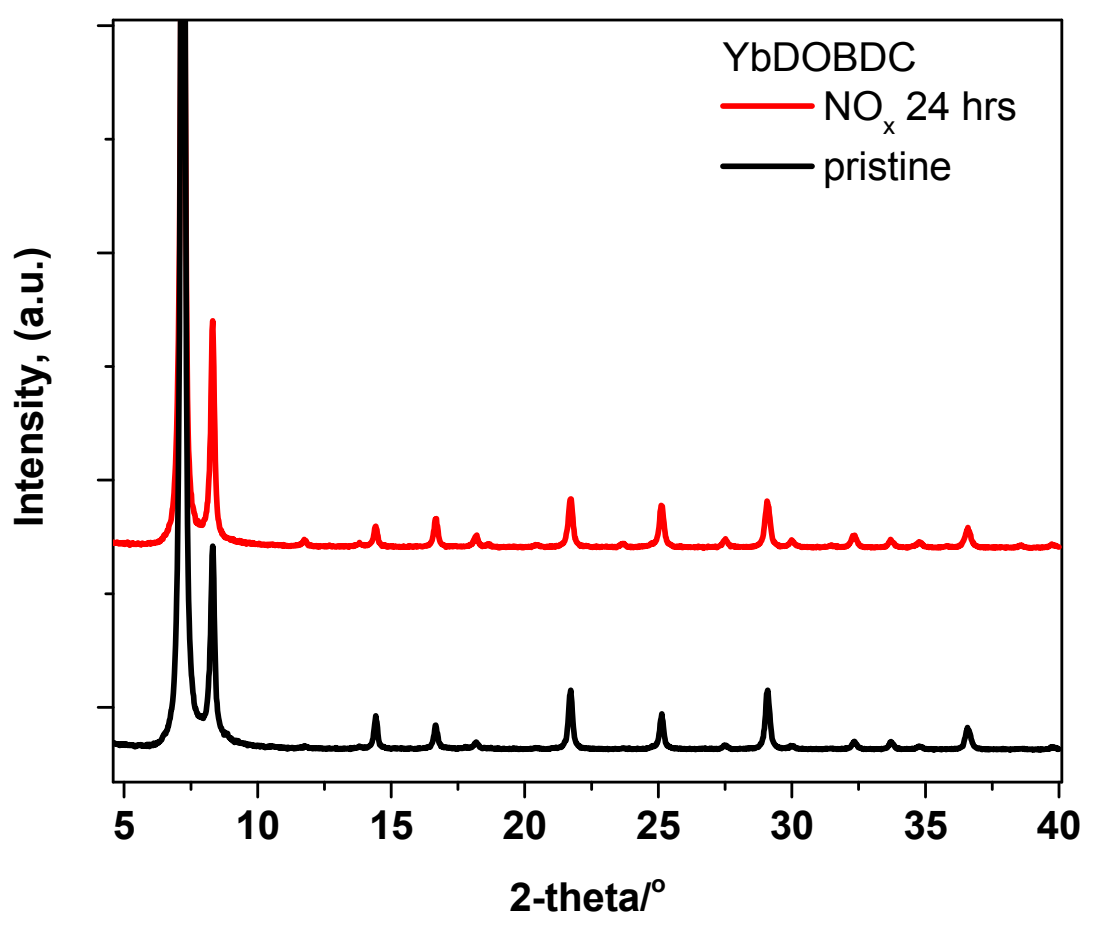


Figure S2. X-ray diffraction data for pristine and $\mathrm{NO}_{\mathrm{x}}$ exposed compound 3 after 24 hrs.

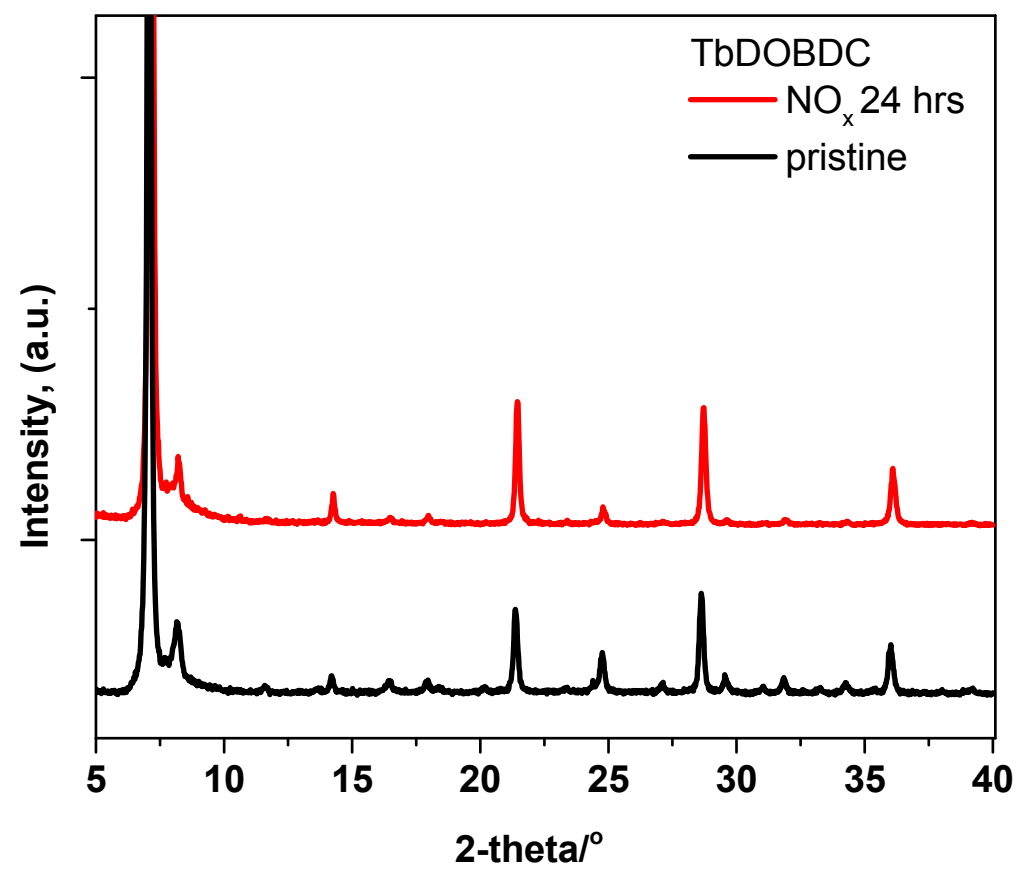

Figure S3. X-ray diffraction data for pristine and $\mathrm{NO}_{\mathrm{x}}$ exposed compound 4 after $24 \mathrm{hrs}$.

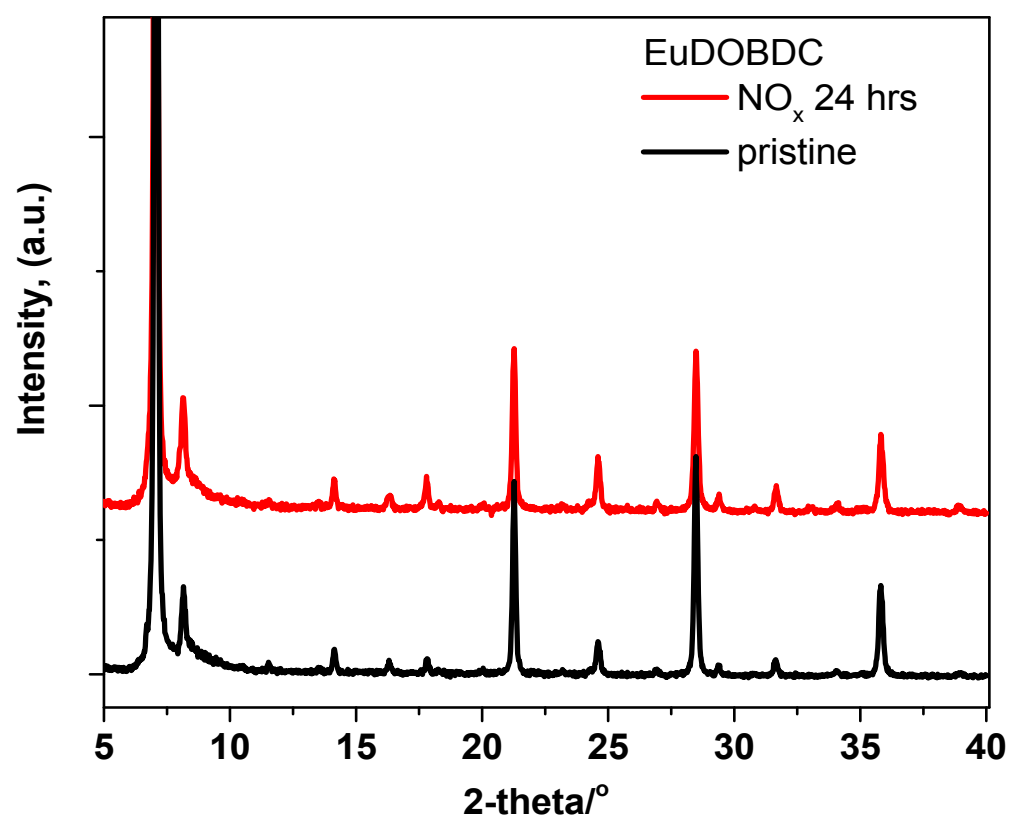

Section S2: Fourier Transform Infrared (FT-IR) Spectroscopy 
Figure S4. FR-IR spectra data for pristine and $\mathrm{NO}_{\mathrm{x}}$ exposed compound 2 after 24 hrs.

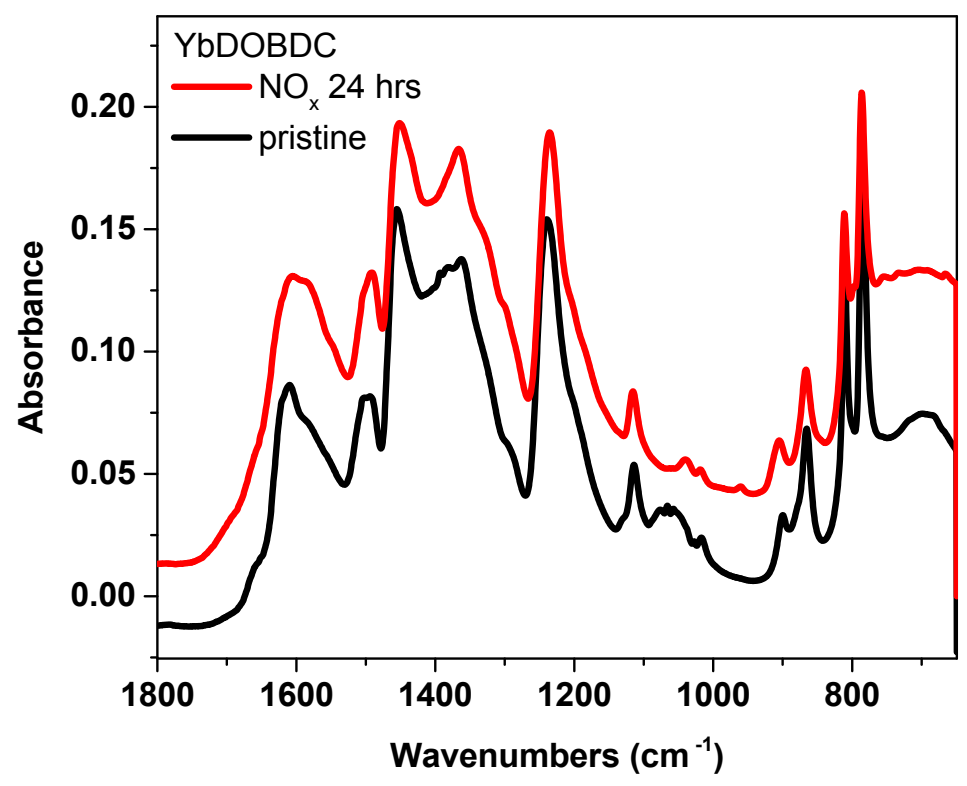

Figure S5. FR-IR spectra data for pristine and $\mathrm{NO}_{\mathrm{x}}$ exposed compound 3 after 24 hrs.

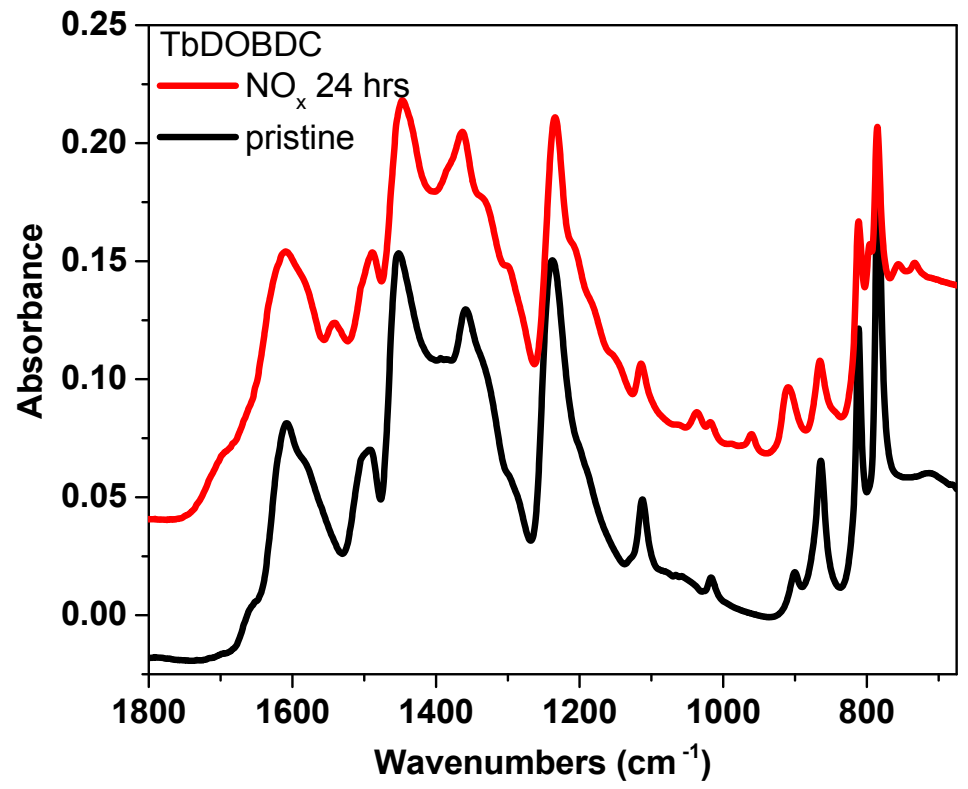

Figure S6. FR-IR spectra data for pristine and $\mathrm{NO}_{\mathrm{x}}$ exposed compound 4 after 24 hrs. 


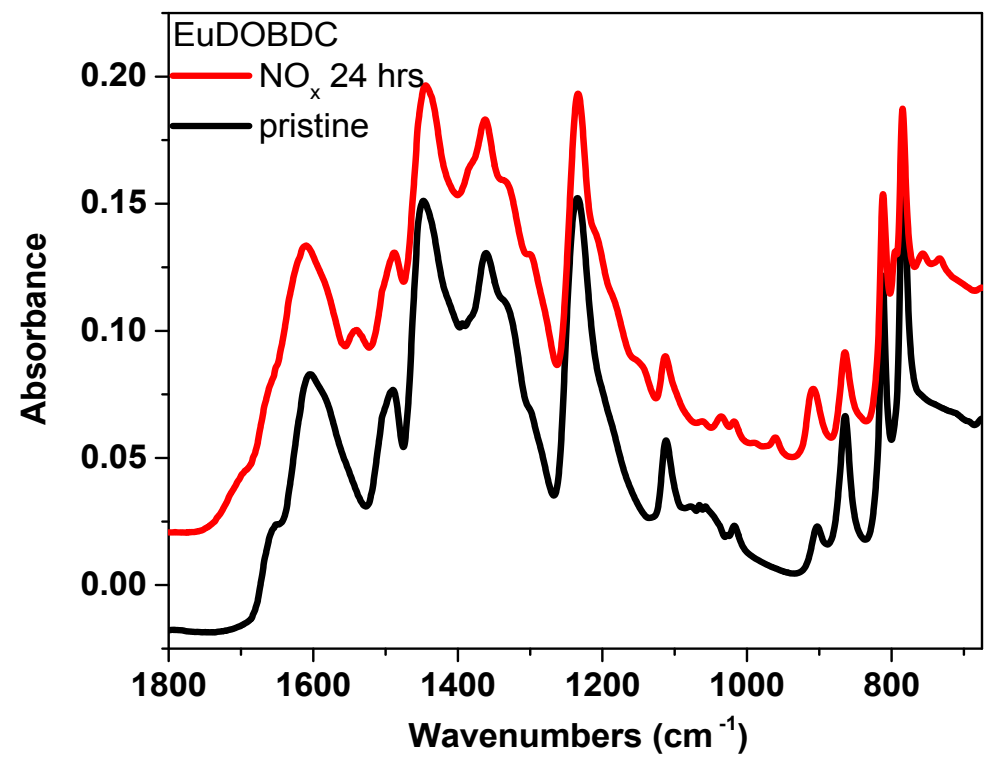

Figure S7. Investigated configurations of $\mathrm{NO}_{\mathrm{x}}$ interaction with the DOBDC ligand. The panels show (a) DOBDC (b) nitro group (c) NO at hydroxyl site (d) NO at carbonyl site (e) $\mathrm{NO}_{2}$ at hydroxyl site and (f) $\mathrm{NO}_{2}$ at the carbonyl site. 


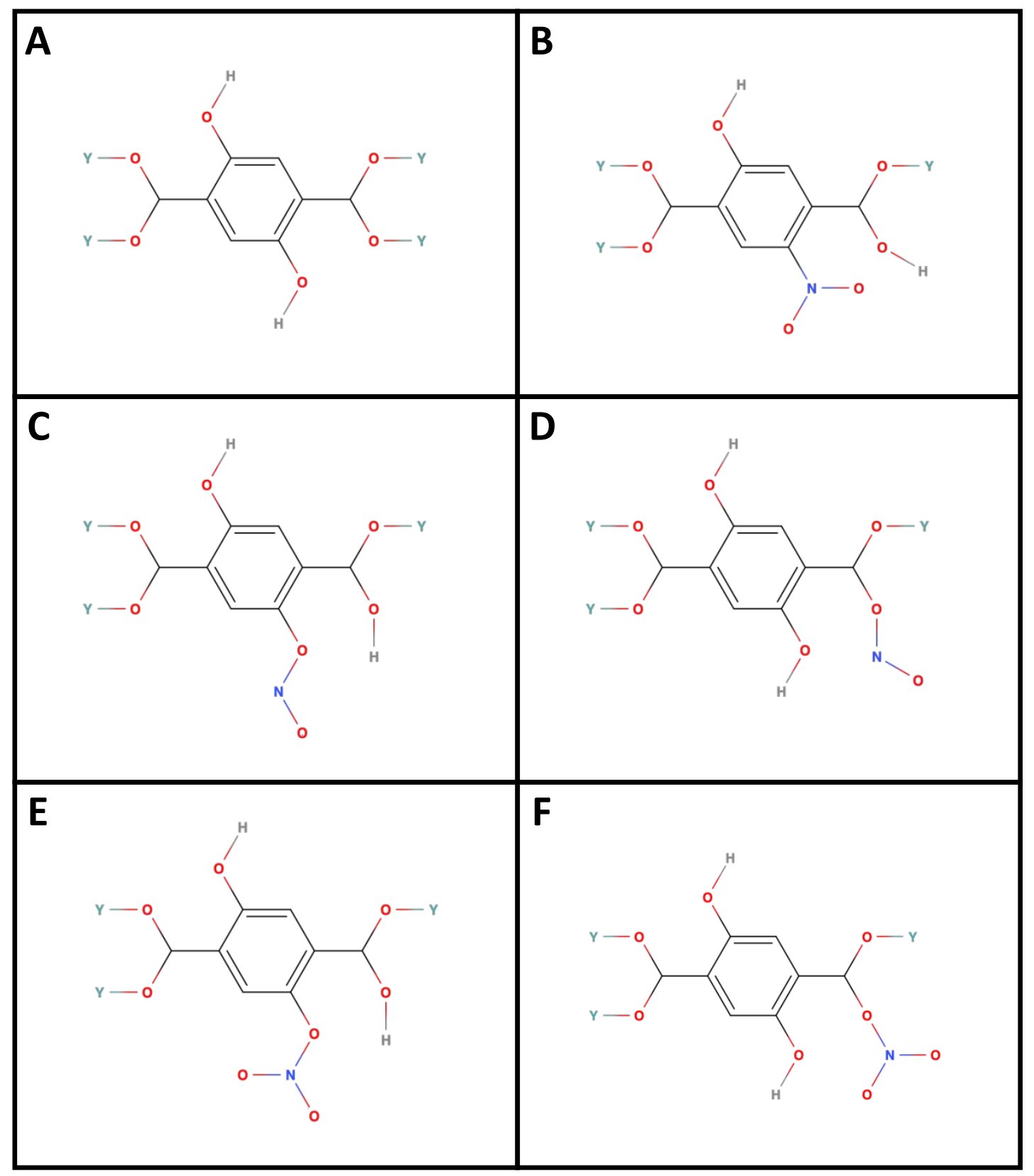

Table S1. Interaction distances and binding energies calculated for $\mathrm{NO}$ and $\mathrm{NO}_{2}$ interaction at hydroxyl and carbonyl sites on a DOBDC linker. 


\begin{tabular}{|c|c|c|c|}
\hline $\begin{array}{c}\mathrm{NO}_{\mathrm{x}} / \text { DOBDC Binding } \\
\text { Configuration }\end{array}$ & Gas & $\begin{array}{c}\text { Interaction } \\
\text { Distance }(\AA)\end{array}$ & $\begin{array}{c}\text { Binding Energy } \\
(\mathrm{kJ} / \mathrm{mol})\end{array}$ \\
\hline $\mathrm{A}$ & - & - & - \\
\hline $\mathrm{B}$ & $\mathrm{NO}_{2}$ & 1.44 & -106.48 \\
\hline $\mathrm{C}$ & $\mathrm{NO}$ & 1.85 & -82.41 \\
\hline $\mathrm{D}$ & $\mathrm{NO}$ & 1.72 & -82.24 \\
\hline $\mathrm{E}$ & $\mathrm{NO}_{2}$ & 1.94 & -41.03 \\
\hline $\mathrm{F}$ & $\mathrm{NO}_{2}$ & 1.61 & -104.60 \\
\hline
\end{tabular}

Section S3: Thermogravimetric-mass spectrometry (TGA-MS) analyses 
The structural thermal stability and species off-gas was investigated by TGA-MS. Measurements used a SDTQ600 TA instrument. Samples were heated at $10^{\circ} \mathrm{C} / \mathrm{min}$ to $800^{\circ} \mathrm{C}$ under nitrogen flow.

Figure S8. TGA-MS for compound 1 before (top) and after 24 hrs $\mathrm{NO}_{\mathrm{x}}$ exposure (bottom).
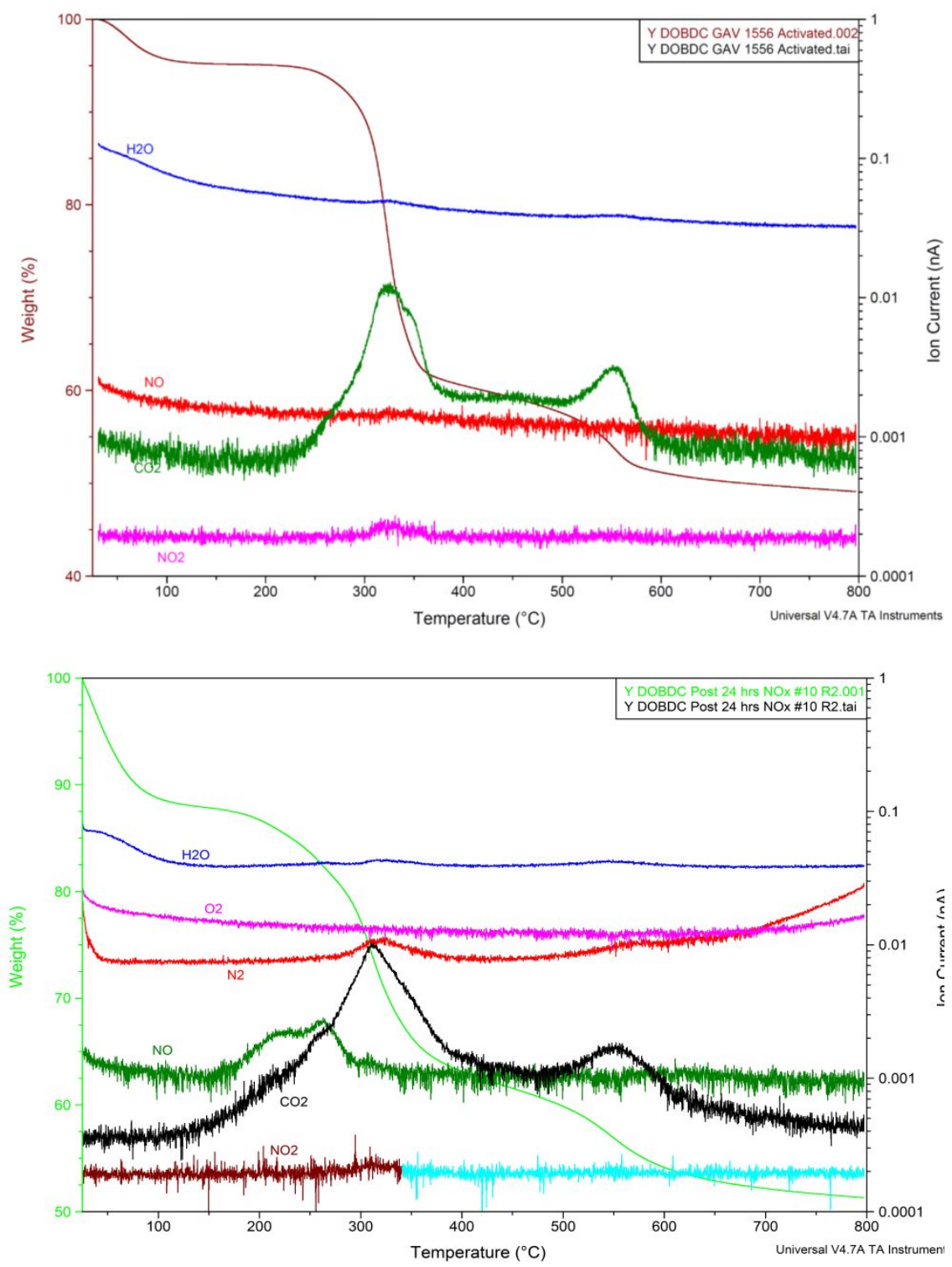

Figure S9. TGA-MS for compound 2 before (top) and after 24 hrs $\mathrm{NO}_{\mathrm{x}}$ exposure (bottom). 

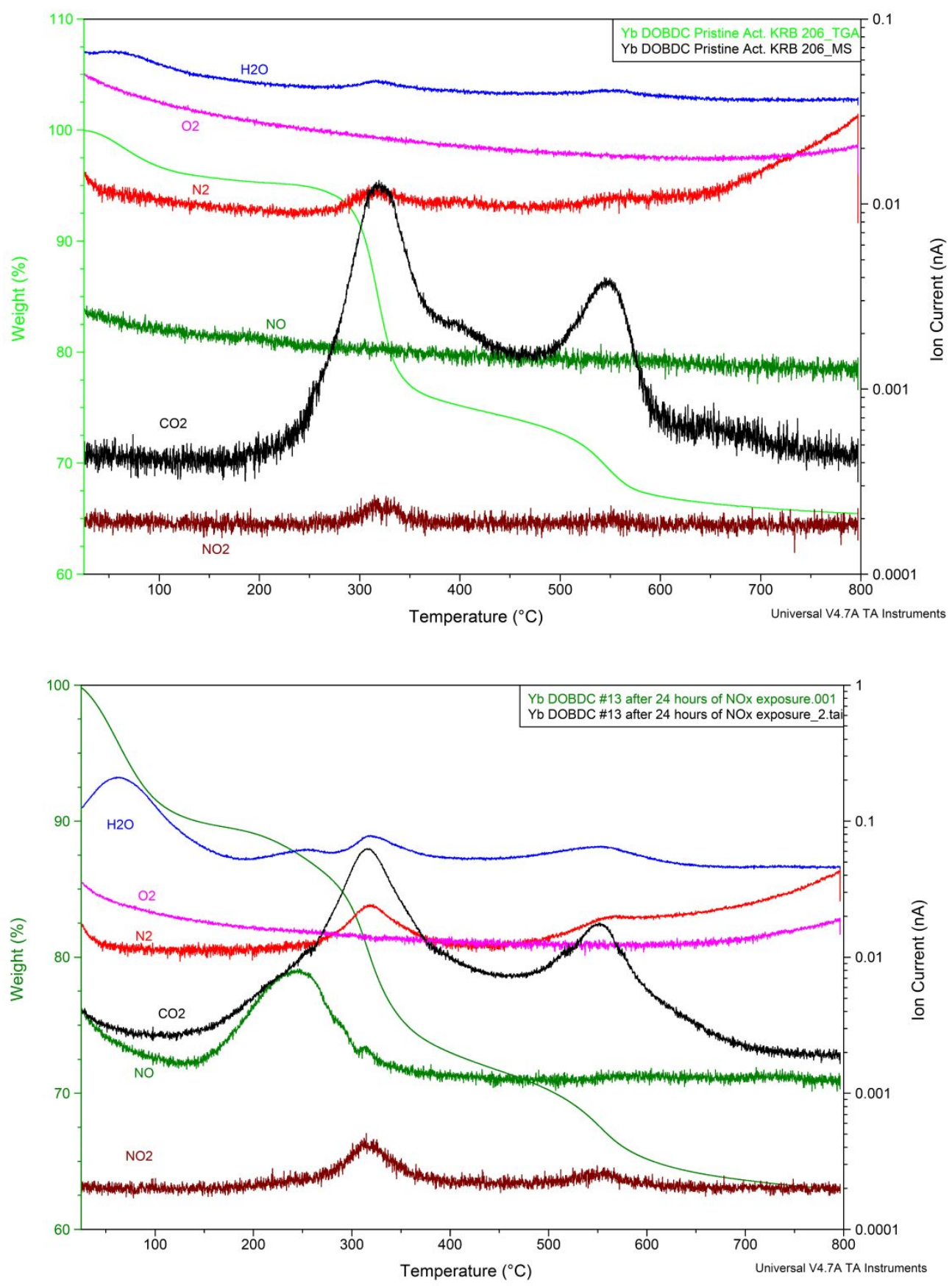

Figure S10. TGA-MS for compound 3 before (top) and after $24 \mathrm{hrs} \mathrm{NO}_{\mathrm{x}}$ exposure (bottom). 

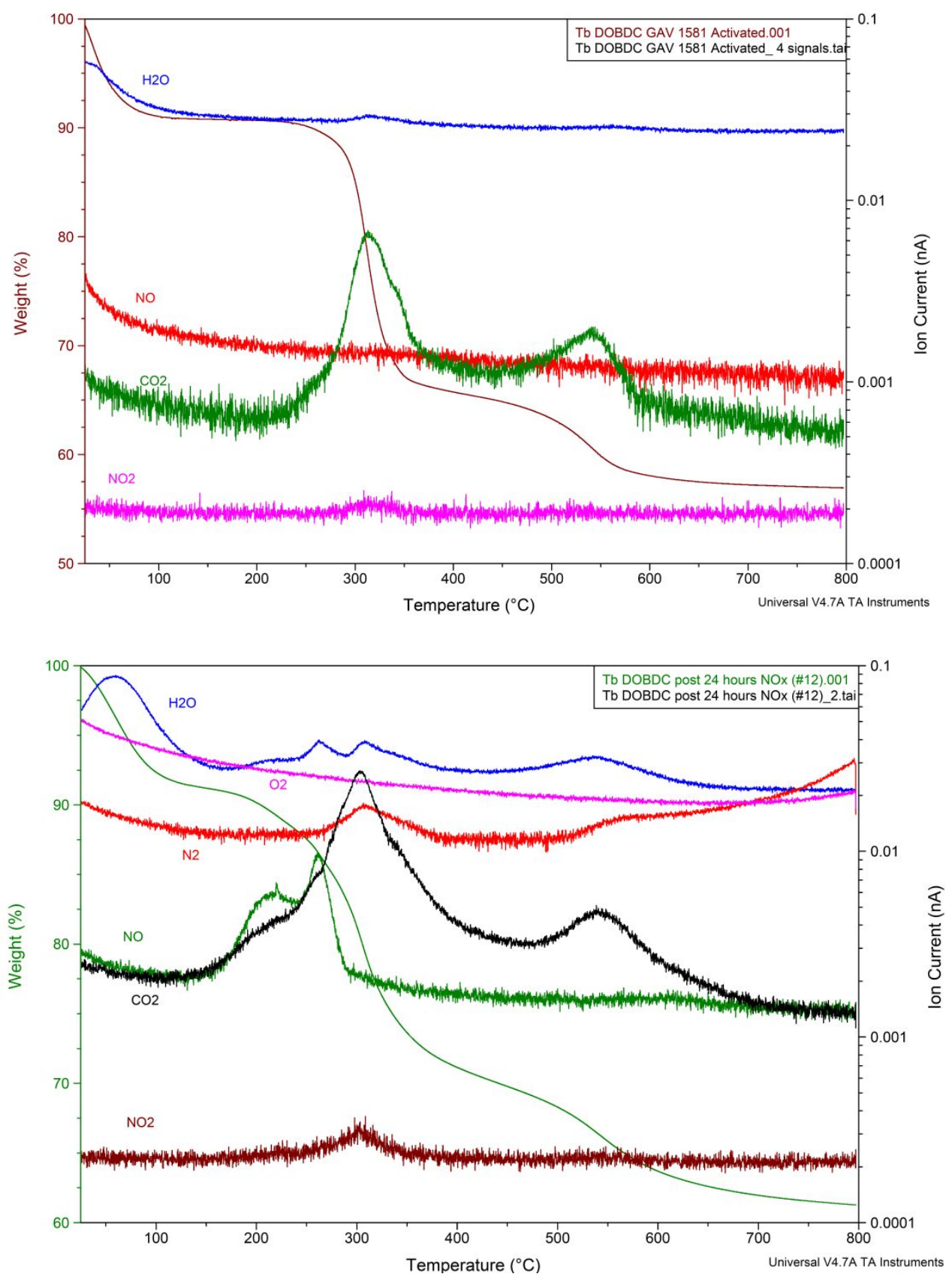

Figure S11. TGA-MS for compound $\mathbf{4}$ before (top) and after $24 \mathrm{hrs} \mathrm{NO}_{\mathrm{x}}$ exposure (bottom). 

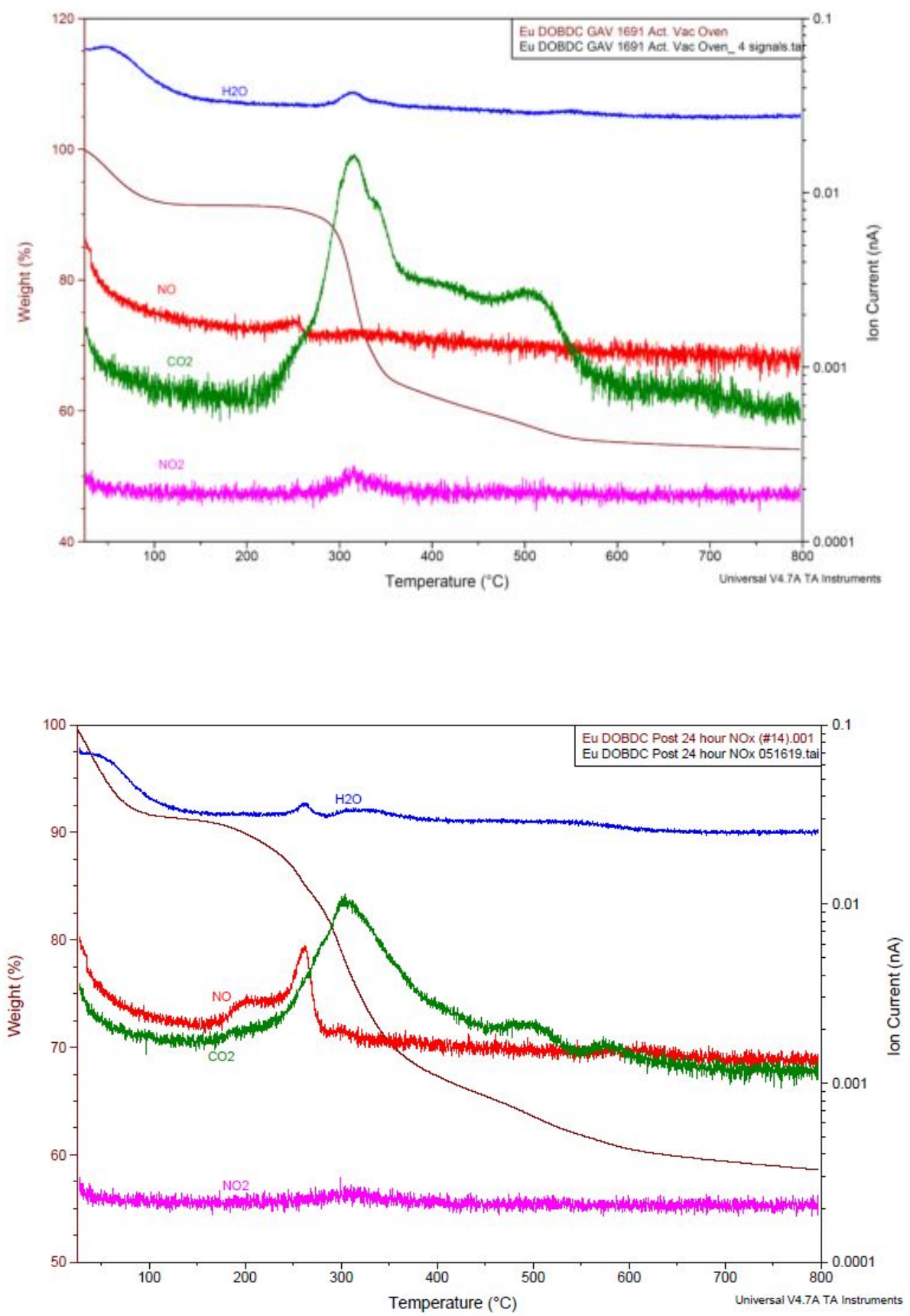

\section{Section S4: Photoluminescent studies}


Figure S12. PL data for compound 2, before and after $24 \mathrm{hrs} \mathrm{NO}_{\mathrm{x}}$ exposure.

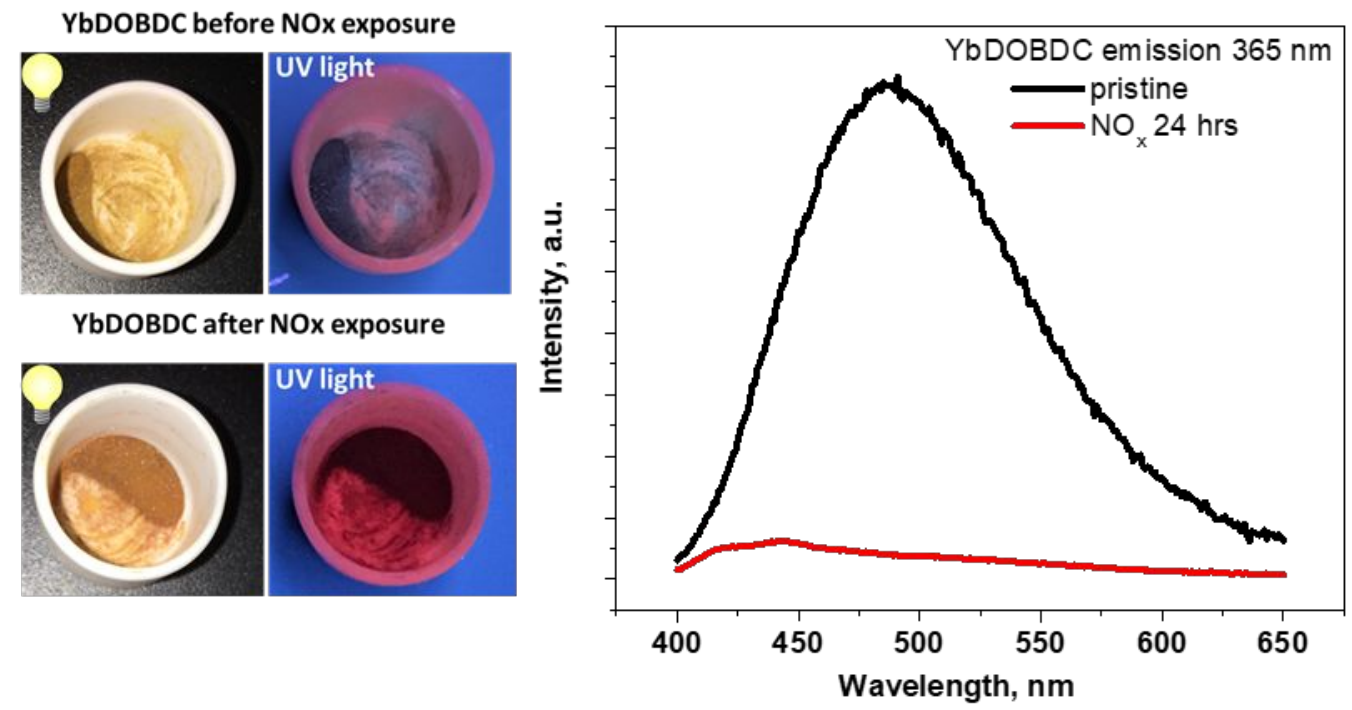

Figure S13. PL data for compound 3, before and after $24 \mathrm{hrs} \mathrm{NO}_{\mathrm{x}}$ exposure.
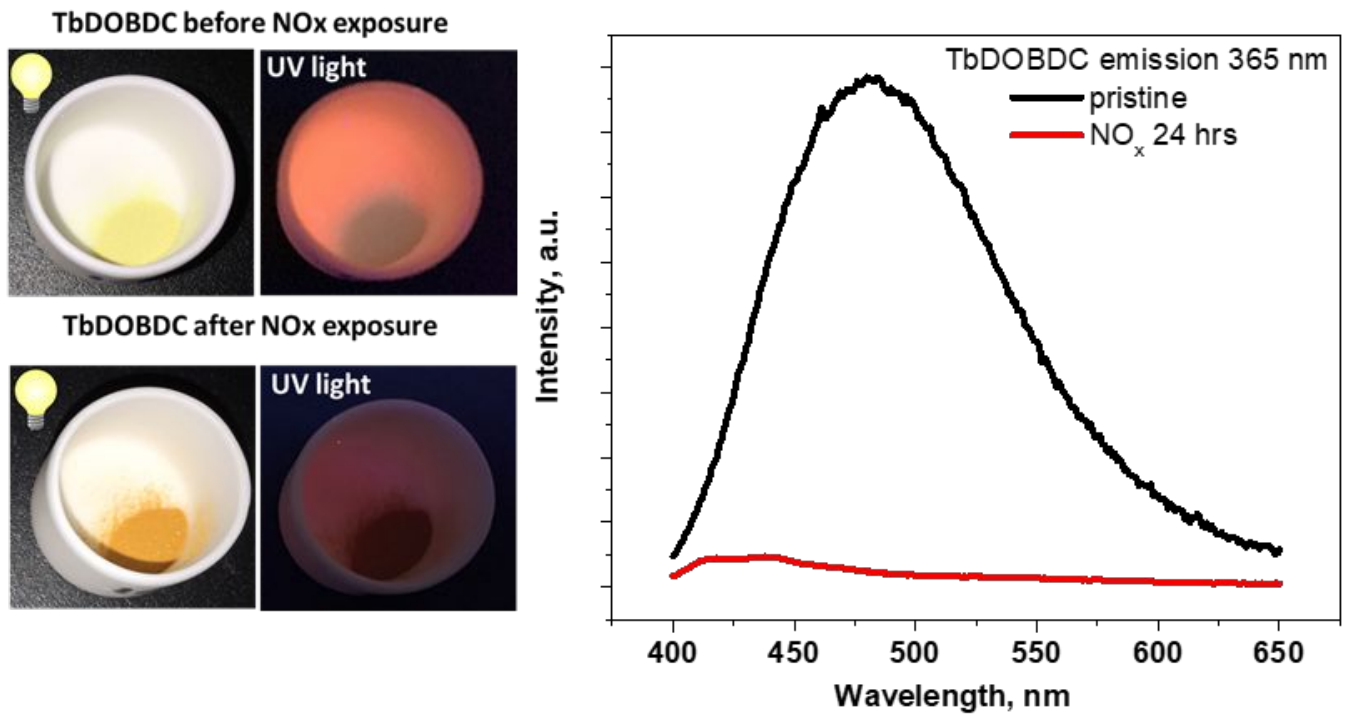

Figure S14. PL data for compound 4, before and after $24 \mathrm{hrs} \mathrm{NO}_{\mathrm{x}}$ exposure. 

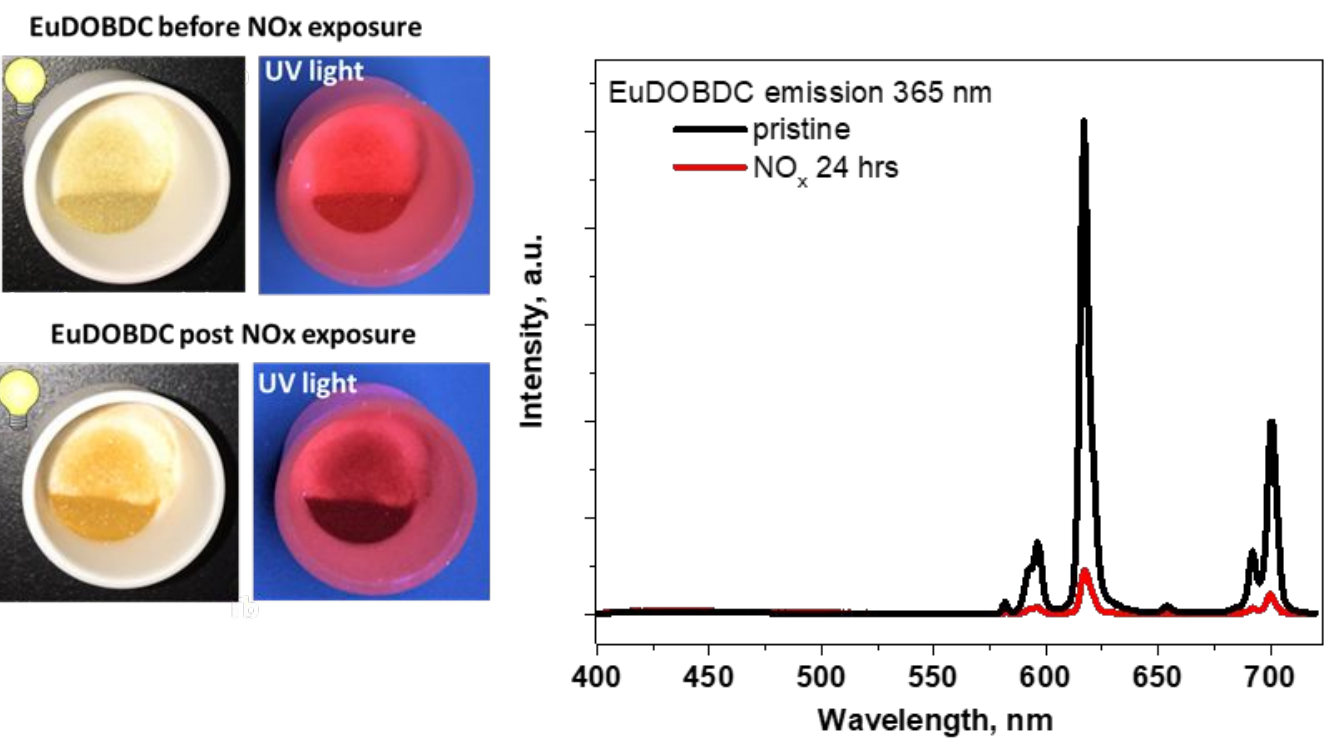

Section S4: Computational Supporting Information 
Figure S15. Absorption spectrum for YDOBDC $+\mathrm{H}_{2} \mathrm{O}$ and YDOBDC $+\mathrm{NO}_{2}$. The highlighted transitions (vertical dashed lines) are identified by value of oscillator strength in Table 1, main manuscript.
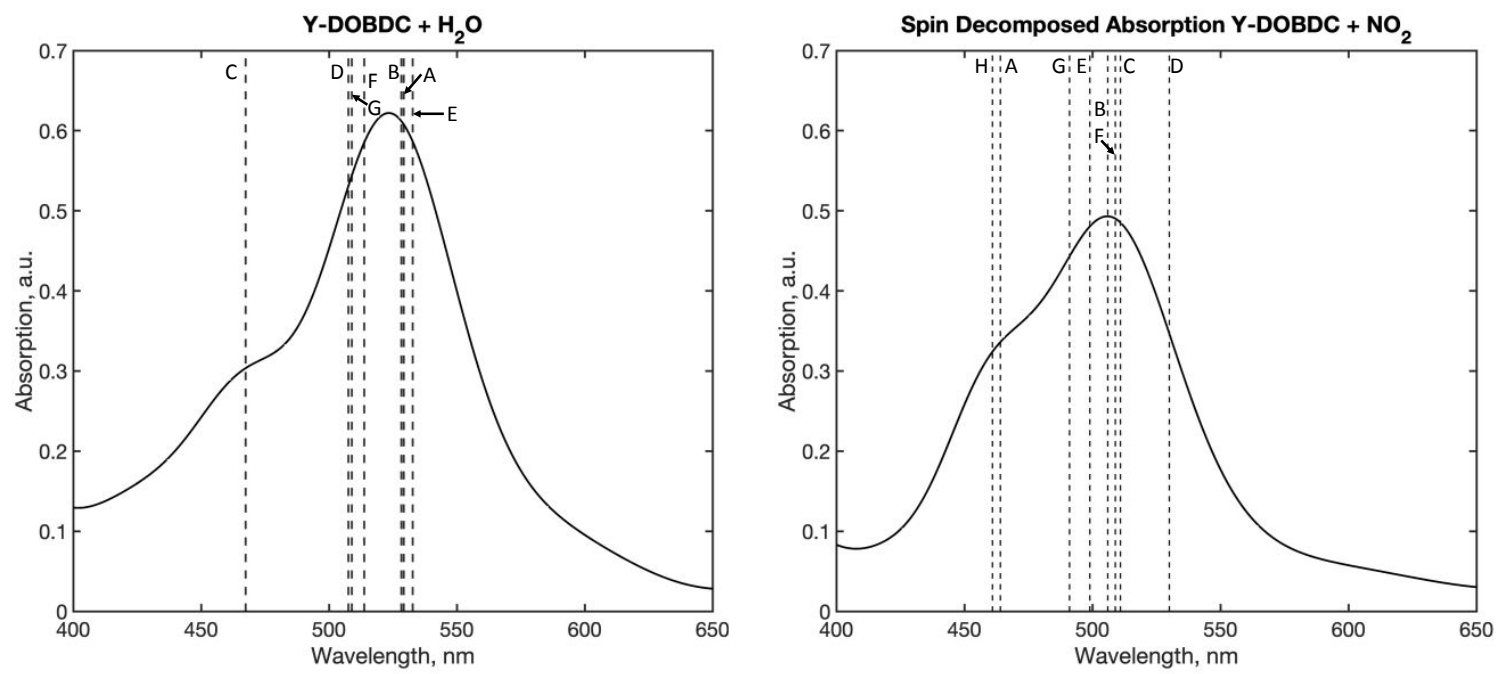
Figure S16. Total density of states comparison for activated YDOBDC and YDOBDC + $\mathrm{NO}_{2}$. The spin-unrestricted DOS are shown for spin alpha (solid) and beta (dashed) of the activated (black) and $\mathrm{NO}_{2}$ (red/blue) systems.

\section{Activated vs $\mathrm{NO}_{2} \mathrm{Y}$-DOBDC}

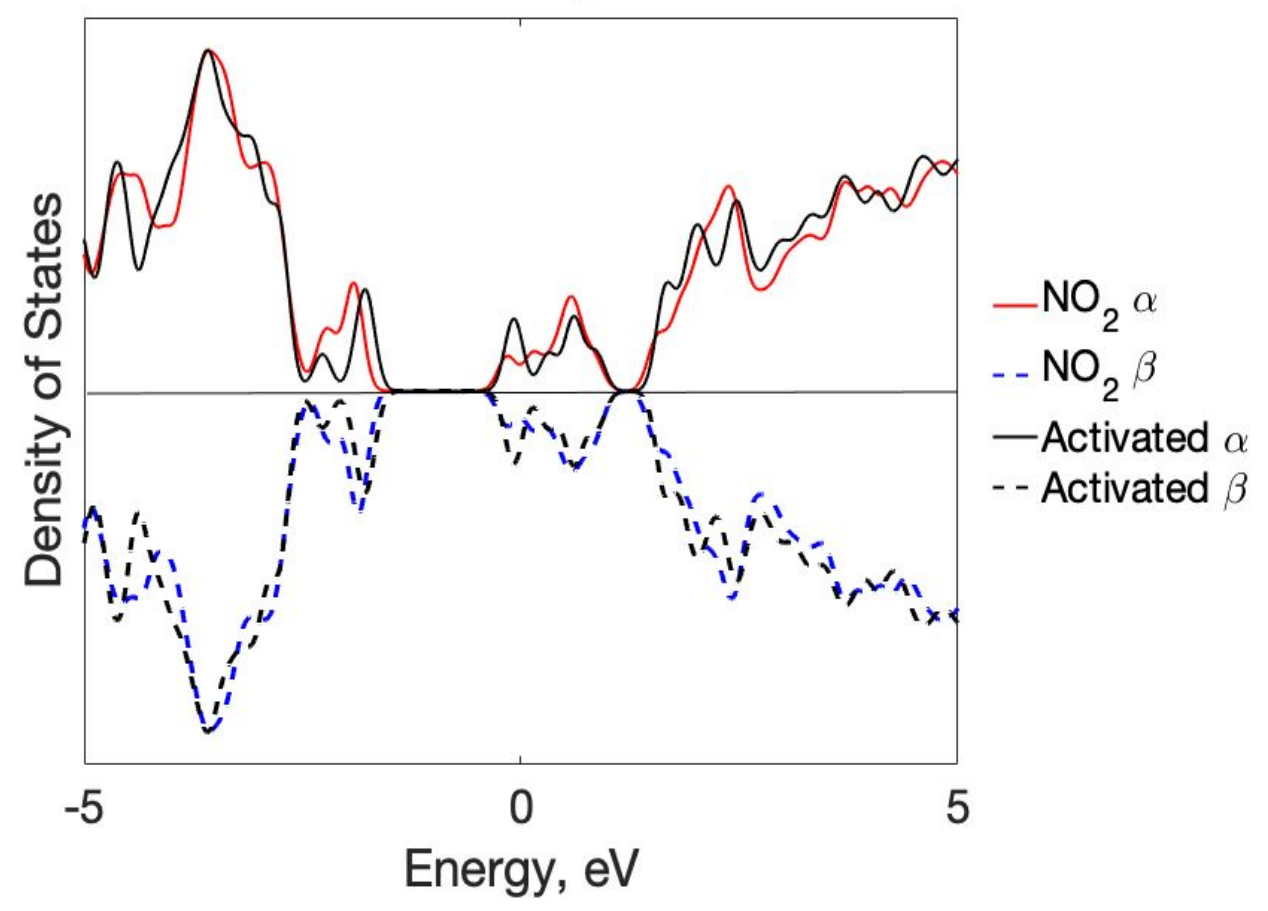


Figure S17. Spin-decomposed calculated absorption spectra for YDOBDC $+\mathrm{NO}_{2}$. The total absorption spectra (solid black) is shown with the spin projection, alpha (dashed blue) and beta (dashed red), contributions to the total absorption spectrum.

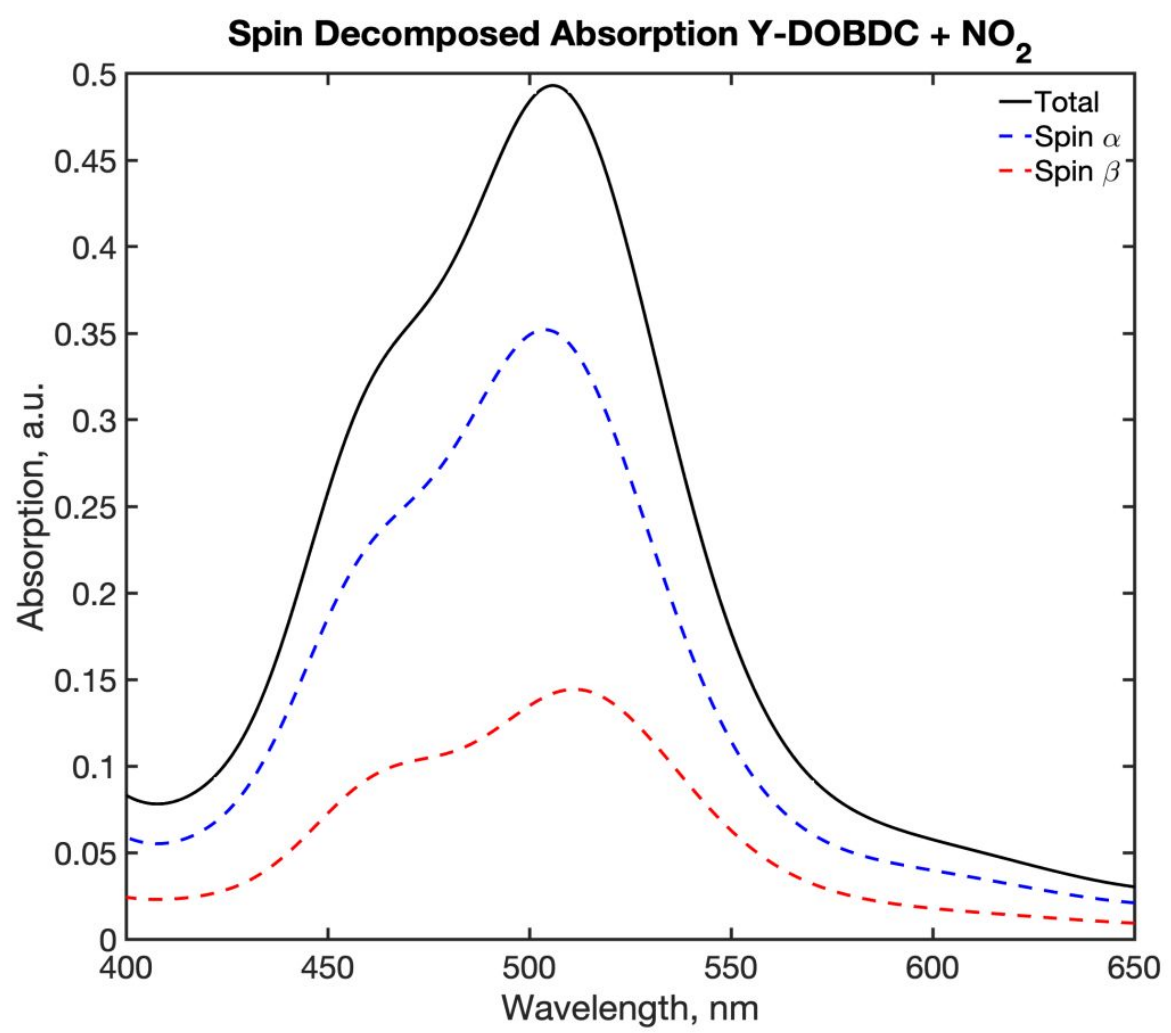


Figure S18. Partial charge densities (yellow isosurface) for transitions at the secondary absorption peak in the 400-650nm range of YDOBDC $+\mathrm{H}_{2} \mathrm{O}$ (top) and $\mathrm{YDOBDC}+\mathrm{NO}_{2}$ (bottom).

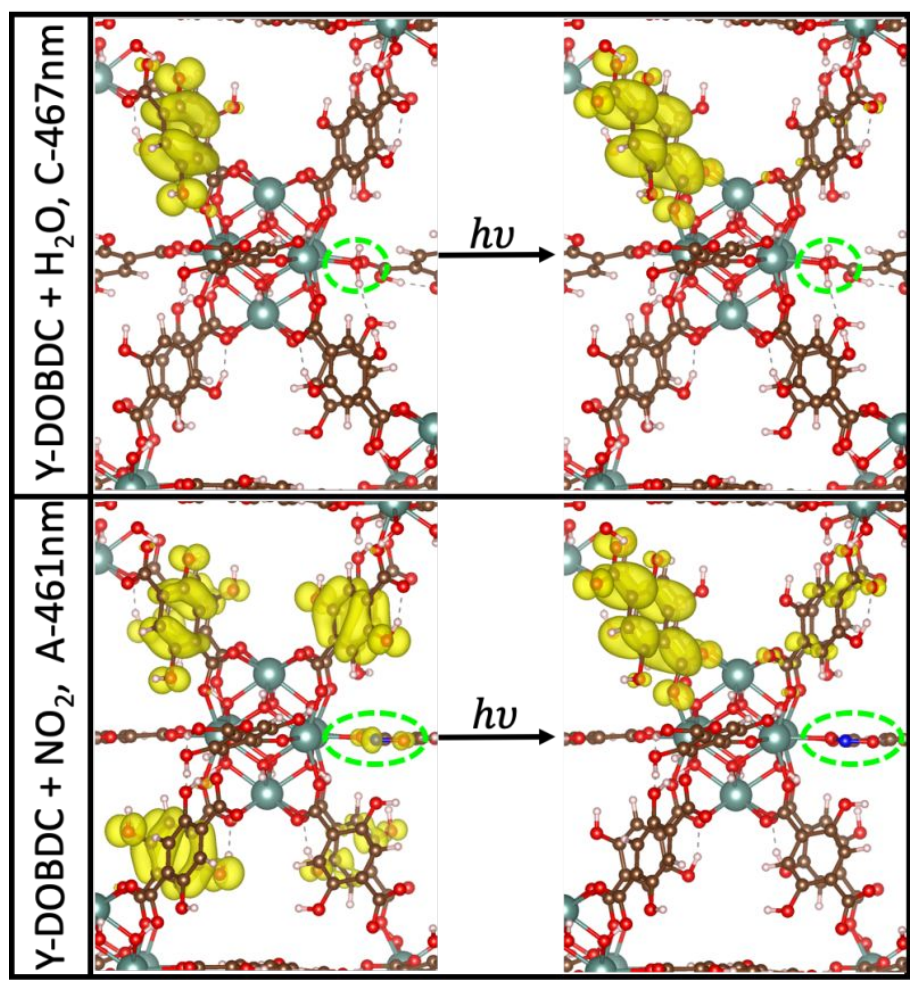

